\title{
ПРОДУКТИВНОЕ ДОЛГОЛЕТИЕ КОРОВ В ЗАВИСИМОСТИ ОТ СИСТЕМЫ СОДЕРЖАНИЯ
}

\author{
I.P. Ivanova, M.E. Grigoryev, V.K. Pilipchuk
}

\section{PRODUCTIVE LONGEVITY OF THE COWS DEPENDING ON THE SYSTEM OF KEEPING}

Иванова Ирина Петровна - канд. с.-х. наук, доц. каф. зоотехнии Омского государственного аграрного университета им. П.А. Столыпина, г. Омск. E-mail: ip.ivanova@omgau.org

Григорьев Максим Евгеньевич - студ. 2-го курса Омского государственного аграрного университета им. П.А. Столыпина, г. Омск.

E-mail: me.grigorev1816@omgau.org

Пилипчук Валентина Константиновна - студ. 2-го курса Омского государственного аграрного университета им. П.А. Столыпина, г. Омск. E-mail: vk.pilipchuk1821@omgau.org

Важной задачей в молочном скотоводстве является увеличение продолжительности сроков хозяйственного использования коров. Цель исследований - оценить продуктивное долголетие племенного поголовья коров молочного направления продуктивности в зависимости от принятой технологии содержания животных. Объектом исследования являлось поголовье выбывших коров черно-пестрой и красной степной породы за период 2010-2019 г2. Общее количество исследуемых животных составило 862 головы. Группировку животных проводили с учетом принятой в предприятиях системы содержания дойного стада. Основной причиной выбытия дойных коров из стад являются заболевания категории «прочие», к которым относятся болезни обмена веществ и снижение молочной продуктивности. По этой причине из стада выбраковывается 42,9-44,4 \% от всего выбывшего поголовья. При привязной системе содержания на долю выбывших по причине заболевания конечностей приходится $13,9 \%$, что на 2,2 \% больше, чем при беспривязном содержании, так как животные не страдают заболеваниями конечностей от гиподинамии. Средняя продолжительность продуктивного использования коров в племенных стадах Омской области варьирует от 1031 до
Ivanova Irina Petrovna - Cand. Agr. Sci., Assoc. Prof., Chair of Animal Breeding, Omsk State Agrarian University named after P. A. Stolypin, Omsk.

E-mail: ip .ivanova@omgau.org

Grigoryev Maxim Evgenyevich - 2-Year Student, Omsk State Agrarian University named after P.A. Stolypin, Omsk.

E-mail: m.grigorev1816@omgau.org

Pilipchuk Valentina Konstantinovna - 2-Year Student, Omsk State Agrarian University named after P. A. Stolypin, Omsk.

E-mail: vk.pilipchuk1821@omgau.org

1208 дней. Коровы при привязной системе содержания выбывают из стада на 177 дней раньше, чем при беспривязном содержании $(P<0,01)$. Разница по пожизненному удою коров в разрезе технологии содержания составила 2987 ке, или 20,9 \% в пользу беспривязной системы. По продолжительности продуктивного использования достоверное преимущество имеют коровы, содержащиеся без привязи, разница составила 177 дней, или 17,2 \%.

Ключевые слова: продуктивное долголетие, система содержания, молочная продуктивность, селекция.

An important task in dairy farming is to increase the duration of economic use of cows. The purpose of the study was to assess the productive longevity of breeding dairy cows depending on the adopted technology of animal keeping. The object of the study was the number of retired cows of black-andwhite and red steppe breeds for the period of 20102019. The total number of the animals studied made 862 heads. Grouping of animals was carried out taking into account the system of keeping dairy herds adopted by the farms. The main reasons for the retirement of dairy cows from the herds were the diseases of the "other" category, which included metabolic disorders and reduced milk productivity. For 
this reason, 42.9-44.4\% of all livestock were excluded from the herd. With tethered keeping system, the proportion of those who leave due to limb disease accounted for $13.9 \%$, which was $2.2 \%$ more than with a non-tethered keeping system, since the animals did not suffer from limb diseases caused by inactivity. The average duration of productive use of cows in breeding herds of the Omsk Region ranged from 1031 to 1208 days. The cows with a tethered keeping system were removed from the herd 177 days earlier than at tethered system $(P<0.01)$. The difference in the lifetime milk yield of cows in the conditions of the technology of keeping was $2987 \mathrm{~kg}$ or $20.9 \%$ in favor of free-range system. For the duration of productive use, cows kept without a leash had significant advantage; the difference was 177 days or $17.2 \%$.

Keywords: productive longevity, content system, milk productivity, selection.

Введение. Основной вектор селекции в молочном скотоводстве - это повышение обильномолочности маточного поголовья $[1,2]$. Односторонний отбор и гомогенный подбор родительских пар способствуют быстрой реализации цели разведения, но в современном племенном животноводстве, акцентируя внимание только на признаках продуктивности, селекция направлена в ущерб тем признакам, которые способствуют сохранению высокого уровня продуктивности продолжительное время [3]. Выявление причин, которые приводят к снижению сроков продуктивного использования коров, определение задач современной селекции животных являются актуальным направлением в молочном скотоводстве.

Важной задачей в молочном скотоводстве является увеличение продолжительности сроков хозяйственного использования коров и оптимизация продуктивного долголетия. Коровы в стадах не достигают предельного возраста и всегда выбывают раньше возможного срока биологического долголетия [1, 4-6]. Срок использования животных зависит от их продуктивных и племенных качеств и продолжительности пребывания животных в стаде до тех пор, пока их ценные качества сохраняются на высоком уровне $[2,7,8]$. Таким образом, возникает противоречие между высокой продуктивностью животных - основной целью разведения - и продолжительностью их хозяйственного использо- вания - экономической составляющей отрасли молочного скотоводства.

Для решения данной проблемы необходимо определить причины выбытия коров из стада, оценить степень влияния особенностей систем содержания коров на продолжительность их продуктивного использования, выявить взаимосвязь между уровнем молочной продуктивности коров и возрастом их выбытия из стада при различных способах содержания.

Цель исследования. Оценить продуктивное долголетие племенного поголовья крупного рогатого скота молочного направления продуктивности в зависимости от принятой технологии содержания животных.

Материал и методы исследования. Исследования проводились на кафедре зоотехнии ФГБОУ ВО ОмскиЙ ГАУ зоотехническими и статистическими методами. Информационная база составлена по базам «СЕЛЭКС - Молочный скот» племенных предприятий Омской области.

Для анализа причин снижения периода продуктивного использования коров проведен мониторинг причин выбытия коров до наступления хозяйственной зрелости. Продуктивное долголетие коров оценивали по продолжительности жизни, использования, пожизненного удоя и удоя на один день жизни. Объектом исследования являлось поголовье выбывших коров племенных предприятий, занимающихся разведением крупного рогатого скота черно-пестрой и красной степной породы за период 2010-2019 гт. Общее количество исследуемых животных составило 862 головы.

Результаты исследования и их обсуждение. Продуктивное долголетие коров является потенциалом увеличения эффективности ведения молочного скотоводства, поэтому может являться приоритетным направлением селекции.

Причин для выбытия животных из стада достаточно много, и в каждом хозяйстве они имеют свою специфику. Но в целом их объединяют хорошо известные факторы, присущие интенсивной технологии ведения животноводства. Практикуемый высококонцентратный тип кормления, дисбаланс питания, стрессы, гиподинамия, отсутствие солнечной инсоляции лежат в основе глубоких расстройств всех видов обмена веществ, развития иммунодефицитных состояний. Все это снижает защитные силы и адаптационные способности организма. 
Выявление причин, которые приводят к снижению сроков хозяйственного долголетия молочных коров, определение задач современной селекции животных являются актуальным на- правлением. В таблице 1 представлены причины выбытия коров до наступления хозяйственной зрелости в исследуемом предприятии.

\section{Структура причин выбывших животных, \%}

\begin{tabular}{|l|c|c|}
\hline \multicolumn{1}{|c|}{ Заболевания } & $\begin{array}{c}\text { Беспривязная система } \\
\text { содержания }\end{array}$ & $\begin{array}{c}\text { Привязная система } \\
\text { содержания }\end{array}$ \\
\hline Гинекологические и яловость & 29,1 & 26,9 \\
\hline Вымени & 14,8 & 16,3 \\
\hline Конечности & 11,7 & 13,9 \\
\hline Прочие & 44,4 & 42,9 \\
\hline Всего & 100 & 100 \\
\hline
\end{tabular}

Основной причиной выбытия дойных коров из стад являются заболевания категории «прочие», к которым относятся болезни обмена веществ, клинически проявляющиеся быстрым исхуданием, снижением молочной продуктивности. По этой причине из стада выбраковывается 42,9-44,4 \% от всего выбывшего поголовья. При привязной системе содержания на долю выбывших по причине заболевания конечностей приходится 13,9 \%, что на 2,2 \% больше, чем при беспривязном содержании, так как животные страдают заболеваниями конечностей от гиподинамии.
По причине яловости в большей степени выбраковываются коровы при беспривязном содержании, так как затрудняется процесс выявления коров в охоте, а учитывая рост числа «тихих» охот у высокопродуктивных животных, именно они попадают в зону риска быть выбракованными по данной причине [9].

Оценка продуктивного долголетия и пожизненной продуктивности выбывших коров в зависимости от системы содержания животных представлена в таблице 2.

Средняя продолжительность продуктивного использования коров варьирует от 1031 до 1208 дней.

Таблица 2

\section{Оценка продуктивного долголетия и пожизненной продуктивности выбывших коров}

\begin{tabular}{|l|c|c|}
\hline \multicolumn{1}{|c|}{ Показатель } & $\begin{array}{c}\text { Беспривязная система } \\
\text { содержания }\end{array}$ & $\begin{array}{c}\text { Привязная система } \\
\text { содержания }\end{array}$ \\
\hline $\begin{array}{l}\text { Продолжительность хозяйст- } \\
\text { венного использования, дн. }\end{array}$ & $1208 \pm 10,4$ & $1031 \pm 12,1$ \\
\hline Пожизненный удой, кг & $17231 \pm 128$ & $14244 \pm 192$ \\
\hline Удой на 1 день ППИ, кг & $14,27 \pm 0,18$ & $13,82 \pm 0,5$ \\
\hline
\end{tabular}

Установлено значительное превосходство по продолжительности продуктивного использования коров при беспривязной системе содержания. Коровы при привязной системе содержания выбывают из стада на 177 дней раньше, чем при беспривязном содержании $(P<0,01)$. Продолжительность продуктивного использования коров при традиционной системе содержания меньше на $17,2 \%$. Разница по пожизненному удою коров в разрезе технологии содержания составила 2987 кг, или 20,9% в пользу беспривязной системы.

Молочная продуктивность в расчете на один день продуктивной жизни у коров при беспривязном содержании также превышает на 14,9% в сравнении с коровами, которых содержали на привязи. 
Наблюдается отрицательный фенотипический тренд по продуктивности коров и продолжительности их продуктивного использования. Но также отмечается наличие во всех предприятиях животных, отличающихся высокой продолжительностью продуктивного использования, возраст которых превышает 3000 дней, и одновременно имеющих высокую молочную продуктивность, максимальный удой на один день ППИ которых более 20 кг. Таким образом, существует возможность селекции животных по адаптивным способностям, так как в их генотипах закреплен ряд технологических признаков адаптивного характера.

Влияние величины удоя в популяции на продолжительность жизни можно проанализировать, исключив влияние хозяйственно-временных факторов. Для этого в качестве критерия используются дифференциальные показатели продуктивности за 305 дней первой лактации.

Основная масса животных выбывает из стад при продолжительности хозяйственного использования до 1000 дней, что вполне обосновано проводимой селекционной работой, так как вероятность выбытия по причинам браковки селекционером коров после первой лактации выше. Раннее выбытие высокопродуктивных коров происходит по причине несоответствия условий содержания и кормления высокому генетическому потенциалу продуктивности.

Также установлена корреляционная зависимость между продолжительностью продуктивного использования и продуктивными качествами коров. На основе корреляционного анализа выявлена отрицательная взаимосвязь между продолжительностью хозяйственного использования и удоем за первую лактацию в стадах привязного содержания. Таким образом, чем выше удой за первую лактацию у коровы при привязном содержании, тем раньше она окажется в числе выбывших животных.

Относительно высокая взаимосвязь между продолжительностью продуктивного использования коров и максимальным удоем $(0,45-0,54)$ свидетельствует о проводимом отборе во всех исследуемых хозяйствах на увеличение молочности животныХ.

При беспривязном содержании коэфффициенты корреляции по данным признакам ниже на $33,3 \%$, чем при традиционной системе содер- жания, что свидетельствует о влиянии селекции коров при беспривязном содержании на увеличение молочной продуктивности без сокращения сроков продуктивного использования.

Выводы. По продолжительности продуктивного использования достоверное преимущество имеют коровы, содержащиеся без привязи, разница составила 177 дней, или 17,2\%. Выявлена отрицательная корреляционная взаимосвязь между обильномолочностью и продолжительностью продуктивного использования коров в стаде при привязной системе содержания.

Таким образом, полученные результаты свидетельствуют о влиянии технологических особенностей ведения отрасли скотоводства на продолжительность продуктивного использования маточного поголовья, а так как в каждом предприятии имеется определенное поголовье, сочетающее высокую молочную продуктивность на протяжении 5 и более лактаций, необходимо разрабатывать селекционные программы по максимальному использованию данных генотипов в разведении молочного скота.

\section{Литература}

1. Иванова И.П., Троценко И.В. Репродуктивные функции коров в зависимости от технологии содержания в условиях Омской области // Главный зоотехник. 2019. № 8. C. 12-19.

2. Лефлер Т.Ф., Растопин В.Г. Биологические особенности и продуктивное долголетие коров красно-пестрой породы разных производственных типов // Вестник КрасГАУ. 2009. № 1 (28). С. 87-91.

3. Литовченко И.П. Селекционно-генетические параметры в популяции черно-пестрого скота в Омской области и использование их в племенной работе: автореф. дис. ... канд. с.-х. наук. Уфра, 2007. 20 c.

4. Русских Т.А., Бычкова В.А., Юдин В.М. Продуктивное долголетие коров черно-пестрой и холмогорской пород // Пермский аграрный вестник. 2019. № 1 (25). С. 123-130.

5. Скворцова Е.Г., Неверова О.П., Чепуштанова О.В. Продуктивное долголетие коров черно-пестрой породы и причины их выбытия // Аграрный вестник Урала. 2019. № 5 (184). C. 54-61. 
6. Чеченихина О.С., Степанова Ю.А. Стрессоустойчивость и показатели продуктивного долголетия коров разных пород // Молочнохозяйственный вестник. 2019. № 4 (36). C. $133-140$.

7. Белозерцева С.Л., Петрухина Л.Л. Влияние возраста и живой массы при первом отеле на продуктивное долголетие коров // Казанская наука. 2010. № 9. С. 64-66.

8. Руденко О.В. Значение паратипических факторов в формировании продуктивного долголетия красных горбатовских коров // Аграрная наука Евро-Северо-Востока. 2019. T. 20. № 1 (25). C. 273-282.

9. Черных А.Г., Юрченко Е.Н., Иванова И.П. Селекционно-генетические параметры оценки молочной продуктивности коров в стаде СПК «Большевик» // Российский электронный научный журнал. 2014. № 3 (9). С. $78-88$

\section{Literatura}

1. Ivanova I.P., Trocenko I.V. Reproduktivnye funkcii korov $v$ zavisimosti ot tehnologii soderzhanija v uslovijah Omskoj oblasti /I Glavnyj zootehnik. 2019. № 8. S. 12-19.

2. Lefler T.F., Rastopin V.G. Biologicheskie osobennosti i produktivnoe dolgoletie korov krasno-pestroj porody raznyh proizvodstvennyh tipov // Vestnik KrasGAU. 2009. № 1 (28). S. 87-91.
3. Litovchenko I.P. Selekcionno-geneticheskie parametry v populjacii cherno-pestrogo skota v Omskoj oblasti i ispol'zovanie ih v plemennoj rabote: avtoref. dis. ... kand. s.-h. nauk. Ufa, 2007. $20 \mathrm{~s}$.

4. Russkih T.A., Bychkova V.A., Judin V.M. Produktivnoe dolgoletie korov cherno-pestroj $\mathrm{i}$ holmogorskoj porod // Permskij agrarnyj vestnik. 2019. № 1 (25). S. 123-130.

5. Skvorcova E.G., Neverova O.P., Chepushtanova O.V. Produktivnoe dolgoletie korov chernopestroj porody i prichiny in vybytija // Agrarnyj vestnik Urala. 2019. № 5 (184). S. 54-61.

6. Chechenihina O.S., Stepanova Ju.A. Stressoustojchivost' i pokazateli produktivnogo dolgoletija korov raznyh porod // Molochnohozjajstvennyj vestnik. 2019. № 4 (36). S. 133-140.

7. Belozerceva S.L., Petruhina L.L. Vlijanie vozrasta i zhivoj massy pri pervom otele na produktivnoe dolgoletie korov // Kazanskaja nauka. 2010. № 9. S. 64-66.

8. Rudenko O.V. Znachenie paratipicheskih faktorov $v$ formirovanii produktivnogo dolgoletija krasnyh gorbatovskih korov // Agrarnaja nauka Evro-Severo-Vostoka. 2019. T. 20. № 1 (25). S. 273-282.

9. Chernyh A.G., Jurchenko E.N., Ivanova I.P. Selekcionno-geneticheskie parametry ocenki molochnoj produktivnosti korov $\mathrm{v}$ stade SPK «Bol'shevik» // Rossijskij jelektronnyj nauchnyj zhurnal. 2014. № 3 (9). S. 78-88. 